\title{
Surgery for Colorectal Cancer - Trends, Developments, and Future Perspectives
}

\author{
Markus Rentsch Tobias Schiergens Andrej Khandoga Jens Werner \\ Department of General, Visceral, Transplantation Surgery, University of Munich, Campus Großhadern, Munich, Germany
}

Keywords

Colorectal cancer - Surgical treatment · Resection ·

Advanced cancer stage - Complete mesocolic resection . Hyperthermic intraperitoneal chemotherapy, HIPEC

\section{Summary}

Background: Although colorectal surgery is long established as the mainstay treatment for colon cancer, certain topics regarding technical fine-tuning to increase postsurgical recurrence-free survival have remained a matter of debate throughout the past years. These include complete mesocolic excision (CME), treatment strategies for metastatic disease, significance of hyperthermic intraperitoneal chemotherapy (HIPEC), and surgical techniques for the treatment of colorectal cancer recurrence. In addition, new surgical techniques have been introduced in oncologic colorectal surgery, and their potential to provide sufficiently radical resection has yet to be proven. Methods: A structured review of the literature was performed to identify the current state of the art with regard to the mentioned key issues in colorectal surgery. Results: This article provides a comprehensive review of the current literature addressing the above-mentioned current challenges in colorectal surgery. The focus lies on the impact of CME and, in relation to this, on lymph node dissection, as well as on treatment of metastatic disease including peritoneal spread, and finally on the treatment of recurrent disease. Conclusion: Uniformly, the current literature reveals that surgery aiming at complete malignancy elimination within multimodal treatment approaches represents the fundamental quantum leap for the achievement of longterm tumor-free survival.

(c) 2016 S. Karger GmbH, Freiburg

\section{Introduction}

More than 65,000 people will be diagnosed with colorectal cancer (CRC) in Germany in 2016, and more than one-third of them will not survive. However, data of the German Federal Statistics Office (Destatis) show a clear trend towards lowered mortality from CRC (fig. 1). Furthermore, the cumulative number of patients hospitalized for CRC exceeds 80,000 per year. Given the fact that surgical removal of colon cancer represents the only curative option, and R0 resections, particularly in metastatic situations, dramatically impacts long-term survival [1], these data illustrate the importance of surgical therapy in most treatment concepts for CRC [2].

Interestingly, the general principles of colorectal surgery have remained unchanged over many years [1,3-6]. Thus, colorectal surgery and especially its technical aspects can seem like an everyday routine set of procedures. The main goals of surgical treatment for CRC are avoidance of recurrence and metastatic spread, treatment of complications, and maintenance of quality of life.

However, certain subtle differences in surgical treatment practices exist, which have become the subject of debate in recent years.

The most relevant differences in our view include:

i) Optimal lymph node yield and related to it complete mesocolic excision (CME) for colon cancer (this question has been answered for stage II and III rectal carcinoma since total mesorectal excision (TME) has become standard);

ii) Applicability of laparoscopic surgical strategies, including single incision laparoscopic surgery (SILS), natural orifice transluminal endoscopic surgery (NOTES), and robotic laparoscopic surgery;

iii) Strategies to surgically treat colorectal metastatic disease as well as peritoneal spread; and

iv) Strategies for the surgical removal of extensive recurrent colorectal disease.

This article provides insights into the current level of knowledge addressing these issues. For this purpose, PubMed, EMBASE, and 
Fig. 1. Current data regarding developments in CRC-related hospital cases and mortality.
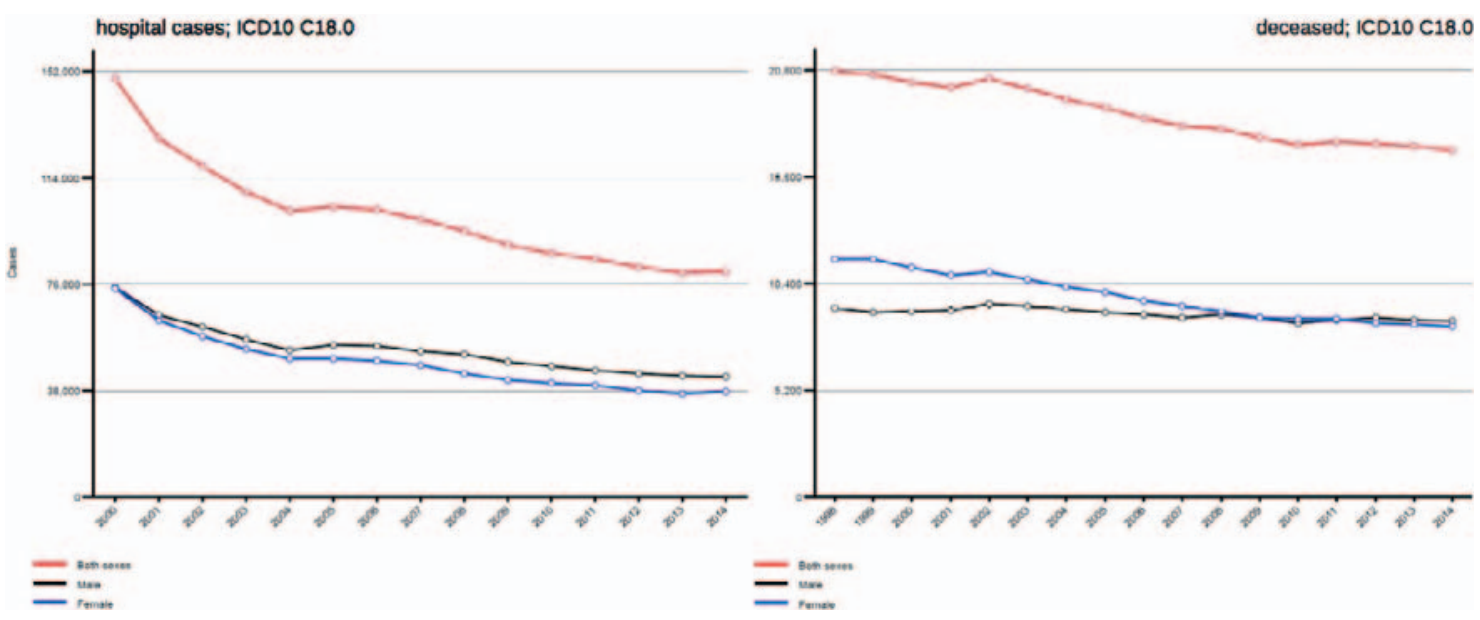

public search engines were searched for relevant literature on the current state of the art regarding the management of CRC. Search terms were 'colorectal cancer' and 'surgery' combined with the terms of the subheadings of this manuscript, namely 'resection', 'CME' and 'TME', 'lymph node dissection', 'hepatic metastases', pulmonary metastases', 'peritoneal metastases', 'HIPEC', and 'recurrent disease' or 'relapse'. The time period covered was 2000 2016. A total of 99 articles were identified pertaining to current surgical strategies. Search results relevant to the above topics have been amended with personal clinical experience in ord†er to give a comprehensive overview of up-to-date treatment options and future perspectives.

\section{Current Surgical Treatment Strategies for Colorectal Cancer}

\section{Lymph Node Dissection}

Without doubt, en bloc excision of the lymphatic drainage of the tumor, including the lymph nodes located therein, has been shown to fundamentally influence the long-term prognosis after surgery for CRC. In this regard, it has been clearly shown by several groups that an increasing number of lymph nodes examined by pathologists correlates with better survival [6-8]. This has even been shown in patients without lymph node involvement. Apart from these observations, the total number of removed lymph nodes appears to reflect only half the truth about the correlation between lymph node involvement and survival. Rather, the number of examined lymph nodes mirrors an appropriate processing of the specimen by the pathologist allowing stratification in terms of future risk of metastatic disease. In addition, increased colon cancer survival has been shown to be associated with a decreasing ratio of metastatic to examined lymph nodes $[9,10]$. In these studies, the number of examined lymph nodes ranged between 11 and 25, which appears rather low and may be easily achieved with a standardized excision technique combined with CME (and TME in rectal cancer) in the mesocolic plane with central vascular ligation [11].
Indeed, several studies have suggested improved quality of surgical specimens and oncologic outcome following CME for colon cancer [12]. As with TME, the CME concept involves the complete removal of the intact mesentery and high ligation of the vascular supply at its point of origin (fig. 2a-c) [13]. Thereby, the embryological planes are respected during surgery. However, in contrast to TME, routine implementation of CME has not yet been achieved. Many studies have reported increased lymph node harvest, less morbidity, reduced locoregional recurrence, and extended cancerspecific survival with CME [12]. This might result in an upstaging of patients and in a higher number of patients for whom chemotherapy is indicated. However, some authors suggest that routine implementation may cause longer operation times [13], which cannot be supported based on our center's experience. The majority of available evidence was generated by retrospective series. West et al. [11] evaluated resection specimens from a center where CME is routinely performed and compared them to standard specimens from another center. The CME specimens were shown to be more frequently resected in the correct anatomic plane and to have a higher lymph node count. Storli et al. [14] reported improved 3 -year overall ( 88 vs. $79 \%$; $\mathrm{p}=0.003$ ) and disease-free survival ( 82 vs. $74 \% ; \mathrm{p}=0.026$ ) when $\mathrm{CME}$ was applied. Cancer-specific survival tended to be better ( 95 vs. $90 \% ; \mathrm{p}=0.067$ ). In another study, Galizia et al. [15] observed that locoregional recurrence was not experienced in CME patients compared to non-CME patients (21\%). The risk of cancer-related death was decreased by over one half in CME patients. However, the CME group was also characterized by significantly higher operation time and blood loss. Furthermore, there were significantly more early cancer stages in the CME group. In a retrospective population-based study by Bertelsen et al. [16] (Danish Colorectal Cancer Group), the CME group showed better 4-year disease-free survival (86\%) than the conventional resection group $(76 \%, \mathrm{p}=0.001)$. Especially patients with stage I and II disease seemed to benefit from CME. As there are multiple causes of potential bias regarding the survival benefit from CME in these retrospective studies, these comparisons should be interpreted with caution [13]. Thus, as data from large multicenter randomized trials are missing, CME has not yet been introduced as a 

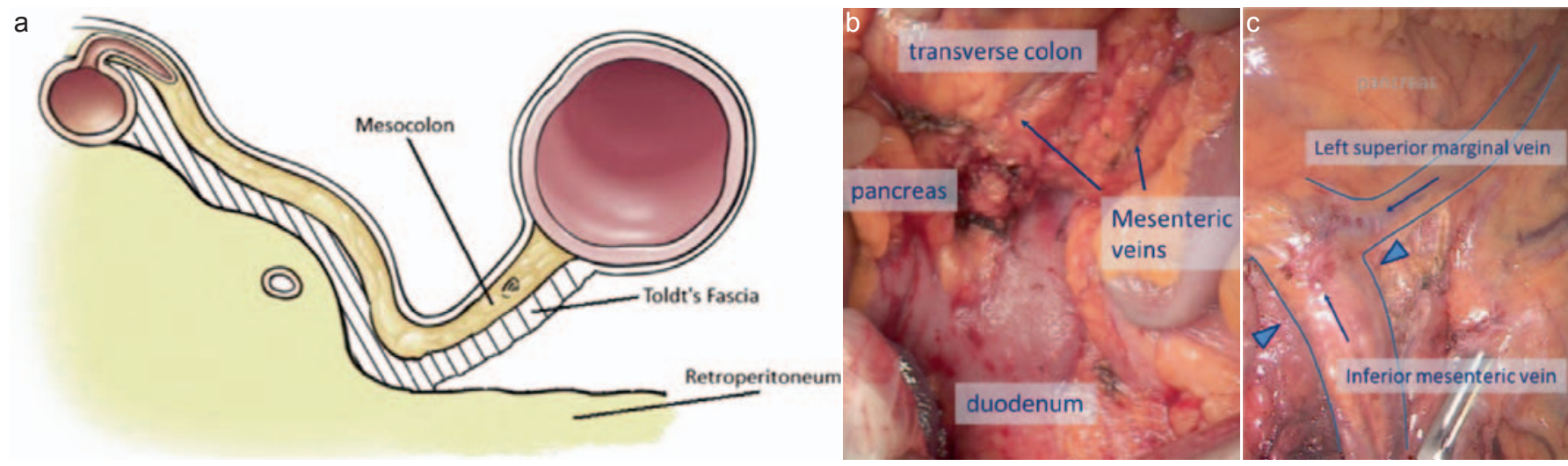

Fig. 2. a Schematic illustration of the anatomic plane for complete mesocolic excision (CME) in right-sided hemicolectomy. b Crucial intraoperative step for CME in right-sided hemicolectomy. Mesocolon and mesoileum have to be mobilized along Toldt's fascia to the duodenum and lower edge of the pancreas. The vascular trunks of the middle (transverse) colon and ileal artery/vein are the dissection margins to the left. c Crucial intraoperative step for CME in sigmoid resection hemicolectomy. The inferior mesenteric vein should be divided at the lower edge of the pancreas (triangles); the left superior marginal vein may be preserved for improved venous drainage of the relocated descending colon and left colic flexure. Note that the pancreas is still covered by the mesenteric section of the transverse colon.

standard approach. However, increasing evidence indicates that implementation of CME surgery would improve outcomes for colon cancer patients.

TME, however, was proposed many years earlier by Heald [3], and represents a fundamental improvement in the resection of rectal tumors. Nowadays, the completeness of the TME, and with that the quality of surgical tumor removal, may be expressed as the pathologic circumferential resection margin (pCRM). An intact and complete PCRM has been identified to lower local recurrence rates, whereas it may not impact on the development of distant metastases $[17,18]$.

\section{Can an Appropriate Lymph Node Number and Ratio Be Gained} with Laparoscopic Techniques?

In numerous studies, concerns that a minimally invasive approach may compromise survival by failing to achieve proper oncologic clearance and adequate staging or by altering the pattern of recurrence could be alleviated. Besides cosmetic aspects, similarity in short-term patient-related benefits such as reduction in narcotics and oral analgesics as well as earlier resumption of bowel activity and hospital discharge has been demonstrated in multiple trials [19-23]. More importantly, there were no significant differences in overall disease-free survival and time to recurrence, as well as port or wound site metastases for laparoscopic-assisted techniques [2428]. To date, laparoscopic surgical techniques for cancer of the sigmoid and rectum represent an established component of the work of every colorectal surgery department. Although technically feasible with the same quality and reproducibility, minimally invasive surgery for upper colon sections, such as the right-, transverse-, and left-sided colon, never became accepted as clinical standard in the same way as resections of the rectosigmoid. To date, in Germany only $10 \%$ of colon resections are performed as minimally invasive surgery, whereas approximately $30 \%$ of sigmoid resections are performed laparoscopically. A Cochrane systematic review was performed including 12 randomized clinical trials involving 3,346 patients for the analysis of long-term outcome of open versus laparoscopic CRC resection. Analyzing only colon cancer cases, no significant difference for recurrence at the primary tumor site, general tumor recurrence, or tumor-related mortality was detected [29].

Furthermore, it has to be pointed out that the most important aspect for the postsurgical oncologic prognosis - an appropriate lymph node yield within en bloc resection with CME - may also be achieved with laparoscopic surgery $[19,24,30]$.

Further laparoscopic techniques such as SILS or NOTES have been proven to be efficient techniques and are discussed in detail in a separate article of this issue.

\section{Treatment Strategies in Advanced Stages of Colorectal Cancer}

Treatment regimens for advanced stages of CRC are markedly more complex and require a differentiated strategy compared to the treatment of a primary CRC without local complications.

The metastatic spread arising from CRC may be categorized into three main forms: i) hepatic metastasis; ii) pulmonary metastasis; and iii) peritoneal carcinosis.

\section{Hepatic Metastasis}

Characteristic forms of occurrence must be distinguished. First of all, metastases may occur metachronously or synchronously according to the primary diagnosis; second, the disease may occur in an oligometastatic as well as diffuse pattern, and those may be resectable, resectable after pretreatment, or non-resectable. Surgical resection of hepatic metastatic CRC became one of the crucial anchors of treatment impacting patient prognosis. Recently, it was impressively shown that the advances in interdisciplinary treatment concepts have led to a marked improvement in long-term survival 
[31]. However, with these multimodal concepts, some recent findings have to be taken into account. First of all, in the surgical treatment of colorectal hepatic metastases, achievement of an R0 situation appears to be mandatory for a positive long-term prognosis even in the era of perioperative chemotherapy [32-36]. However, in some patients, resectability criteria may not be fulfilled at the time of diagnosis, but may be achieved by reducing the size and/or number of the metastases preoperatively. This requires chemotherapy and/or additional local ablative therapy as pretreatment [37-41]. However, if bowel obstruction by the primary cancer complicates or inhibits effective further treatment, its prompt resection or a decompressing stoma to prevent an ileus are indicated.

Depending on the local stage and the intrahepatic tumor burden, sequential or synchronous resection of malignant lesions may be considered. The question of whether the primary colon cancer or the metastasis should be resected first still remains a matter of debate. In clinical situations with dominant hepatic tumor burden compared to the primary cancer, a liver-first approach is recommended. This approach should especially be considered when neoadjuvant or adjuvant chemotherapy regimens with the aim of hepatic tumor control are likely to fail. This strategy was invented in the face of the facts that surgical treatment of the primary would delay liver resection, radiochemotherapy for the primary tumor in rectal cancer is ineffective to control large hepatic metastases, and resection of the primary stimulates growth of the hepatic metastases [42].

However, it was shown that concomitant hepatic and colon resections may slightly decrease perioperative morbidity, with similar overall survival and quality of life [39, 43, 44]. In these studies, no sufficient data was made available on progression-free survival. Other studies revealed no difference with regard to hospital stay and perioperative morbidity $[45,46]$. In summary, simultaneous resections appear to be recommendable for patients with limited hepatic disease. In this context, the 2-stage liver resection may be combined with a simultaneous approach for the colon and liver. For example, if the liver displays bilobar metastatic disease with a high malignant burden on one side (supposedly with decreased metabolic function of this hepatic lobe), resection of the affected segment(s) may be performed simultaneously to the resection of the primary tumor, with subsequent chemotherapy (to counteract the hypertrophy stimulus on liver metastases on the contralateral side), followed by a definitive tumor clearance resection in the remnant liver. To achieve total tumor clearance in metastatic CRC, all strategies to improve resectability, i.e. portal vein embolization with hepatic hypertrophy on the contralateral side or the 'associating liver partition and portal vein ligation' technique, may be utilized as individually adjusted treatment concepts [47-54].

\section{Pulmonary Metastatic Disease}

Equally, patients with pulmonary metastasis may benefit from surgical resection [55-57]. However, patient selection plays a crucial role with regard to prognosis. It has been shown that the number of nodules resected is associated with long-term survival. Other

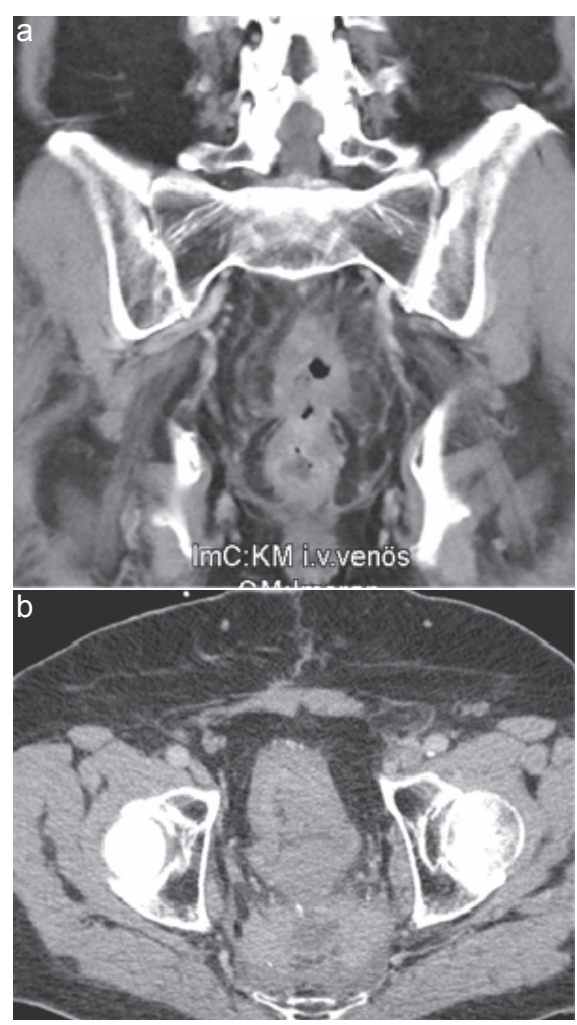

Fig. 3. Images of a 77-year-old man presenting with a second local recurrence of a rectal carcinoma. $\mathrm{He}$ was treated with sacropelvic excision and for mation of a descendos toma plus ileum conduit with urostoma following repeated radiation therapy and chemotherapy.

authors have shown that bilobar dissemination, requiring surgery for complete removal, was not associated with any survival benefit [57]. In small series, a benefit following pulmonary resection was also shown in disease stages with combined metastatic spread [58, 59] as well as in patients with recurrent pulmonary metastases.

\section{Recurrent Disease}

Compared to situations requiring surgery for primary tumors, treatment of recurrent CRC frequently requires multimodal strategies (fig. 3). Several studies revealed a clear survival advantage for patients who were eligible for surgery in the case of recurrent rectal carcinoma [60-64] as well as for colon carcinoma [65, 66]. Although recurrence apart from N2 situations or adjacent organ invasion may be rarely expected in intraperitoneal colon carcinoma, a considerable number of cases may present in large-volume centers. A cohort study from Bologna compared 31 vs. 29 patients with predominantly intraperitoneal colon carcinoma receiving chemotherapy or second surgery (mixed indication), respectively [67]. This study revealed a prolongation of disease-free survival by 4 months (not significant) and a markedly longer median overall survival (58.7 vs. 24.0 months; $\mathrm{p}<0.001$ ). However, when no perisurgical chemotherapy was applied, the median overall survival decreased to 30.3 months in the second-surgery group, indicating the importance of multimodal concepts in the treatment of colon carcinoma recurrence. Read et al. [66] observed local recurrence in $4 \%$ of patients over 5 years, and this was associated with the above- 
mentioned lymph node status or tumor extent in $75 \%$ of the patients. In this study, an overall complication rate of $29 \%$ was noted, with $2.1 \%$ grade 5 complications according to the Clavien-Dindo classification. The Sloan Memorial Kettering Cancer Center [66] demonstrated a $40 \%$ recurrence rate at any location after curative surgery for CRC; $75 \%$ of these patients presented with locoregional relapse. In principal, four subgroups of local recurrence should be distinguished: i) anastomotic; ii) mesenteric/lymph node; iii) retroperitoneal; and iv) disseminated peritoneal. Besides age ( $>60$ years) and the primary tumor stage (I and II vs. III and IV), this study of 100 consecutive cases with relapse after primary curative resection of intraperitoneal colon carcinoma revealed a clear benefit for tumor-specific survival when an R0 resection was achieved. Independent factors associated with the possibility of an R0 resection included a low carcinoembryonic antigen level $(<5 \mathrm{ng} / \mathrm{ml})$, perianastomotic disease, and absence of distant disease.

Another study showed that both the total number of metastases and the location of the metastatic disease were associated with prognosis [68]. Survival was strongly associated with overall tumor burden. Interestingly, among patients with a large tumor burden ( $>6$ metastatic lesions), the relative prognostic impact of the anatomic location was lower.

Nevertheless, complete resection remains the most important prognostic factor and should be the goal of treatment for locally recurrent CRC $[63,65,66]$. Multimodal and interdisciplinary treatment including neoadjuvant and adjuvant therapies should be discussed for all patients. Considering the available evidence, even reirradiation should be considered in specific cases [64]. In the case of disseminated disease (type IV recurrence, see above), application of hyperthermic intraperitoneal chemotherapy (HIPEC) should be discussed (see following section). The goal of complete tumor tissue removal is a proven concept that improves survival as compared to alternative methods for the control of local tumor growth [69].

Furthermore, local complications with a risk of pelvic sepsis as a consequence of uncontrolled destruction of adjacent structures may be avoided. Development of rectal carcinoma recurrence might require pretreatment with chemoradiation in order to limit the extent of resection. Recurrent disease has to be expected in $4-11 \%$ of patients at 5 years post-surgery under optimal multimodal treatment conditions, despite primary R0 resection with intact mesorectal fascia [64]. Interestingly, the Stockholm Colorectal Cancer Study Group and the Basingstoke Bowel Cancer Research Project were able to show that individual training of surgeons in the TME technique resulted in a reduction in local recurrence rates from 14 to $6 \%$ [70]. Without such measures, rates of $5-35 \%$ have been reported [69].

As standard surgical procedure with extended intrapelvic tumor recurrence, abdominoperineal rectal excision represents the mainstay of therapy beyond sphincter-sparing procedures. However, large controlled trials repeatedly showed that total abdominoperineal excision, irrespective of the tumor distance from the anorectal verge, was associated with higher rates of positive CRMs and perforation of the mesorectal plane, which might be attributed, at least in part, to the surgical technique, leaving a waist on the specimen in the area of the pelvic levator muscle by anatomic preparation along the mesorectal fascia. Thus, in recent publications, the so-called extralevator abdominoperineal excision (ELAPE) has been propagated [71], involving a cylindrical excision including the narrowing part of the levator muscle. This preparation technique was introduced for extended and low-seated primary tumors; however, it is of particular value in recurrent rectal carcinoma, which, by nature, exceeds the level of the mesorectal fascia in most cases.

For recurrent tumors infiltrating adjacent pelvic structures such as prostate, bladder, vagina, and uterus, complete pelvic exenteration represents the optimal surgical strategy [72-74] (fig. 3). First described by Brunschwig in the 1960s for gynecologic tumors, this technique was adopted to treat extended rectal tumors. It includes the resection of all potentially infiltrated structures, such as bony pelvis, and also, where appropriate, the resection of pelvic vessels with vascular replacement. In keeping with established principles of cancer surgery, the recurrent tumor must be excised en bloc, in continuity with all involved structures, if local control or cure is to be achieved. Absence of tumor infiltration is determined intraoperatively by the pathologist. However, the presence of unresectable extrapelvic generalized disease is generally accepted as a contraindication for curative resection. Clinical symptoms, such as sciatic nerve pain, a frozen pelvis [75], and unilateral leg edema [76], require special attention during preoperative staging with magnetic resonance imaging or high-resolution computed tomography, and are relative contraindications for resection. Ascertained infiltration of the proximal (S1 or higher) lumbosacral spine or lumbosacral plexus/sciatic nerves is considered as the limit of surgical feasibility [77].

In conclusion, optimal tuning of multimodal treatment options including aggressive surgical regimens may result in maximized disease-free survival of approximately $30 \%$ [78-80] and an overall survival of roughly $50 \%$ at 5 years when an $\mathrm{R} 0$ resection for locally recurrent CRC is achieved [78-81].

\section{Peritoneal Carcinomatosis}

More than $10 \%$ of patients present with peritoneal carcinomatosis as a consequence of continuous regional tumor dissemination at the time of initial diagnosis $[82,83]$. About $40 \%$ of patients with CRC develop peritoneal dissemination at some point in the natural history of this disease [84]. Moreover, peritoneal carcinomatosis is a common sign of tumor progression or recurrence. Patients with peritoneal metastases have historically been considered as having incurable disease with merely palliative treatment options including supportive care, palliative surgery, and the best systemic chemotherapy [85]. Survival rates do not exceed 7 months according to the multicenter study EVOCAPE [85] with 5-fluorouracil (5-FU) and leucovorin, reaching up to 23.4 months with modern chemotherapy regimens including oxaliplatin and irinotecan [86]. However, in about $25 \%$ of the cases, there is no evidence of further distant metastasis, and the peritoneal cavity is the only site of meta- 
static disease. This suggests that in those cases, peritoneal carcinomatosis may represent a first site of dissemination.

Therefore, it is not necessarily indicative of generalized disease, and Elias et al. [87] described and popularized several procedures, such as cytoreductive surgery (including peritonectomy) together with HIPEC and early postoperative intraperitoneal chemotherapy (EPIC), to treat peritoneal carcinomatosis [88]. Although preliminary data were viewed with great skepticism, this strategy is the only one that has shown curative benefits in colorectal peritoneal carcinomatosis. In a randomized controlled trial, Verwaal et al. [89] analyzed 105 patients with established peritoneal carcinomatosis of colorectal or appendiceal origin, which were randomly assigned to cytoreductive surgery and HIPEC with mitomycin C followed by systemic chemotherapy (5-FU and leucovorin), or to systemic chemotherapy alone (5-FU and leucovorin) with palliative surgery as needed. Despite the high postoperative mortality rate (8\%), the median disease-specific survival in the HIPEC-treated group was significantly longer (22 vs. 13 months). At a median follow-up of 8 years, $45 \%$ of patients of the HIPEC arm who underwent complete cytoreduction (no residual tumor nodules) were still alive [89]. In another randomized controlled trial, patients following aggressive surgical cytoreduction and systemic therapy (5-FU-based) with or without HIPEC [87] were investigated. Although the 2-year survival rate of patients undergoing HIPEC was about $60 \%$, the difference in survival between the experimental and control groups was not statistically significant. Thus, the effect of HIPEC is not clearly defined, while cytoreduction is most likely to have beneficial effects. A controlled randomized clinical trial to prove this concept is ongoing. Together, these trials as well as several systematic reviews of the literature indicate that i) cytoreduction in combination with HIPEC prolongs median survival of patients with CRC and peritoneal carcinomatosis up to 29 months and the 5-year survival rates up to $19 \%$; ii) survival rates are even higher if the patients undergo complete surgical cytoreduction (median survival 28-60 months, and 5-year survival 22-49\%); and iii) the overall treatment-associated morbidity and mortality rates are relatively high $(23-44 \%$ and $0-12 \%$, respectively) [90-92]. The success of this treatment strategy substantially depends on a careful patient selection $[85,93]$. Candidates should be younger than 70 years with a physiological age of less than 65 years. Severe cardi- orespiratory disease, renal failure, untreated malignant neoplasm or a World Health Organization Index $>2$ are considered contraindications for cytoreduction + HIPEC [93]. Furthermore, all patients selected for cytoreduction with curative intent should not present with progressive disease while on chemotherapy. As mentioned above, the key to successful outcome is an appropriate selection of patients in order to achieve complete cytoreduction, since this is an essential prognostic factor [94]. To this effect, it has been demonstrated that patients with incomplete cytoreduction and residual tumor $\geq 2.5 \mathrm{~mm}$ (completeness of cytoreduction (CC-1) score) do not achieve more than 6 months survival $[95,96]$. Other major prognostic factors associated with worse outcomes are: histopathologic grades 2 and 3 vs. grade 1, Peritoneal Cancer Index $>20$, lymph node-positive primary tumors, and volume of preoperative peritoneal metastases $[88,97,98]$.

Based upon these issues, the current German guidelines for CRC [99] recommend surgical cytoreduction followed by HIPEC in patients with isolated and localized peritoneal carcinomatosis if: i) Peritoneal Cancer Index $<20$; ii) no extra-abdominal metastases are present; iii) macroscopically complete cytoreduction of the tumor is possible; and iv) therapy is provided in specialized centers, preferably in the context of a clinical trial.

\section{Conclusion}

Aggressive surgical strategies with the aim of complete malignancy elimination are associated with improved disease-free as well as overall survival in most cases of primary and secondary CRC. Surgical radicalness must be balanced with the impact on quality of life. Multimodal therapeutic approaches are frequently recommended to achieve a curative situation in combination with high quality of life. New technical developments, including minimally invasive surgery, aiming to increase patient comfort and quality of life have proven their worth in oncologic surgery.

\section{Disclosure Statement}

There are no financial conflicts of any of the co-authors.

\section{References}

1 Hermanek P, Wiebelt H, Riedl S, Staimmer D, Hermanek P: Long-term results of surgical therapy of colon cancer. Results of the Colorectal Cancer Study Group (Article in German). Chirurg 1994;65:287-297.

2 Spreadborough P, Doran C: The current thinking on colorectal cancer. J R Nav Med Serv 2015;101:47-54.

3 Heald RJ: The 'holy plane' of rectal surgery. J R Soc Med 1988;81:503-508.

4 Cohen AM: Surgical considerations in patients with cancer of the colon and rectum. Semin Oncol 1991;18: 381-387.

5 Faucheron JL: Pelvic anatomy for colorectal surgeons. Acta Chir Belg 2005;105:471-474.
6 Lykke J, Jess P, Roikjaer O; Danish Colorectal Cancer Group: Increased lymph node yield is associated with improved survival in rectal cancer irrespective of neoadjuvant treatment: results from a national cohort study. Dis Colon Rectum 2015;58:823-830.

7 Le Voyer TE, Sigurdson ER, Hanlon AL, Mayer RJ, Macdonald JS, Catalano PJ, Haller DG: Colon cancer survival is associated with increasing number of lymph nodes analyzed: a secondary survey of intergroup trial INT-0089. J Clin Oncol 2003;21:2912-2919.

8 Swanson RS, Compton CC, Stewart AK, Bland KI: The prognosis of T3N0 colon cancer is dependent on the number of lymph nodes examined. Ann Surg Oncol 2003;10:65-71.
9 Berger AC, Sigurdson ER, LeVoyer T, et al: Colon cancer survival is associated with decreasing ratio of metastatic to examined lymph nodes. J Clin Oncol 2005;23: 8706-8712.

10 Vaccaro CA, Im V, Rossi GL, Quintana GO, Benati ML, Perez de Arenaza D, Bonadeo FA: Lymph node ratio as prognosis factor for colon cancer treated by colorectal surgeons. Dis Colon Rectum 2009;52:12441250.

11 West NP, Hohenberger W, Weber K, Perrakis A, Finan PJ, Quirke P: Complete mesocolic excision with central vascular ligation produces an oncologically superior specimen compared with standard surgery for carcinoma of the colon. J Clin Oncol 2010;28:272-278. 
12 Kontovounisios C, Kinross J, Tan E, Brown G, Rasheed S, Tekkis P: Complete mesocolic excision in colorectal cancer: a systematic review. Colorectal Dis 2014;17: $7-16$.

13 Willaert W, Ceelen W: Extent of surgery in cancer of the colon: is more better? World J Gastroenterol 2015; 21:132-138.

14 Storli KE, Søndenaa K, Furnes B, Nesvik I, Gudlaugsson E, Bukholm I, Eide GE: Short term results of complete (D3) vs. standard (D2) mesenteric excision in colon cancer shows improved outcome of complete mesenteric excision in patients with TNM stages I-II. Tech Coloproctol 2014;18:557-564.

15 Galizia G, Lieto E, De Vita F, et al: Is complete mesocolic excision with central vascular ligation safe and effective in the surgical treatment of right-sided colon cancers? A prospective study. Int J Colorectal Dis 2014; 29:89-97.

16 Bertelsen CA, Neuenschwander AU, Jansen JE, et al: Disease-free survival after complete mesocolic excision compared with conventional colon cancer surgery: a retrospective, population-based study. Lancet Oncol 2015;16:161-168.

17 Quirke P, Steele R, Monson J, et al: Effect of the plane of surgery achieved on local recurrence in patients with operable rectal cancer: a prospective study using data from the MRC CR07 and NCIC-CTG CO16 randomised clinical trial. Lancet 2009;373:821-828.

18 Kiehlmann M, Weber K, Göhl J, Fietkau R, Agaimy A, Hohenberger W, Merkel S: The impact of surgical quality on prognosis in patients undergoing rectal carcinoma surgery after preoperative chemoradiation. Int J Colorectal Dis 2016;31:247-255.

19 Vennix S, Pelzers L, Bouvy N, Beets GL, Pierie JP, Wiggers T, Breukink S: Laparoscopic versus open total mesorectal excision for rectal cancer. Cochrane Database Syst Rev 2014;4:CD005200.

20 Blackmore AE, Wong MT, Tang CL: Evolution of laparoscopy in colorectal surgery: an evidence-based review. World J Gastroenterol 2014;20:4926-4933.

21 Huibers CJ, de Roos MA, Ong KH: The effect of the introduction of the ERAS protocol in laparoscopic total mesorectal excision for rectal cancer. Int J Colorectal Dis 2012;27:751-757.

22 Li MZ, Xiao LB, Wu WH, Yang SB, Li SZ: Meta-analysis of laparoscopic versus open colorectal surgery within fast-track perioperative care. Dis Colon Rectum 2012;55:821-827.

23 Vlug MS, Wind J, van der Zaag E, Ubbink DT, Cense HA, Bemelman WA: Systematic review of laparoscopic vs open colonic surgery within an enhanced recovery programme. Colorectal Dis 2009;11:335-343.

24 Buunen M, Veldkamp R, Hop WC, et al: Survival after laparoscopic surgery versus open surgery for colon cancer: long-term outcome of a randomised clinical trial. Lancet Oncol 2009;10:44-52.

25 Lacy AM, Delgado S, Castells A, Prins HA, Arroyo V, Ibarzabal A, Pique JM: The long-term results of a randomized clinical trial of laparoscopy-assisted versus open surgery for colon cancer. Ann Surg 2008;248:1-7

26 Taylor GW, Jayne DG, Brown SR, et al: Adhesions and incisional hernias following laparoscopic versus open surgery for colorectal cancer in the CLASICC trial. Br J Surg 2010;97:70-78.

27 Guillou PJ, Quirke P, Thorpe H, et al: Short-term endpoints of conventional versus laparoscopic-assisted surgery in patients with colorectal cancer (MRC CLASICC trial): multicentre, randomised controlled trial. Lancet 2005;365:1718-1726.

28 Clinical Outcomes of Surgical Therapy Study Group: A comparison of laparoscopically assisted and open colectomy for colon cancer. N Engl J Med 2004;350: 2050-2059.
29 Kuhry E, Schwenk W, Gaupset R, Romild U, Bonjer J: Long-term outcome of laparoscopic surgery for colorectal cancer: a cochrane systematic review of randomised controlled trials. Cancer Treat Rev 2008;34: 498-504.

30 Asoglu O, Balik E, Kunduz E, et al: Laparoscopic surgery for rectal cancer: outcomes in 513 patients. World J Surg 2013;37:883-892.

31 Kopetz S, Chang GJ, Overman MJ, et al: Improved survival in metastatic colorectal cancer is associated with adoption of hepatic resection and improved chemotherapy. J Clin Oncol 2009;27:3677-3683.

32 Angelsen JH, Horn A, Eide GE, Viste A: Surgery for colorectal liver metastases: the impact of resection margins on recurrence and overall survival. World J Surg Oncol 2014;12:127.

33 Pandanaboyana S, White A, Pathak S, Hidalgo EL, Toogood G, Lodge JP, Prasad KR: Impact of margin status and neoadjuvant chemotherapy on survival, recurrence after liver resection for colorectal liver metastasis. Ann Surg Oncol 2015;22:173-179.

34 Ayez N, Lalmahomed ZS, Eggermont AM, Ijzermans JN, de Jonge J, van Montfort K, Verhoef C: Outcome of microscopic incomplete resection (R1) of colorectal liver metastases in the era of neoadjuvant chemotherapy. Ann Surg Oncol 2012;19:1618-1627.

35 Tranchart H, Chirica M, Faron M, et al: Prognostic impact of positive surgical margins after resection of colorectal cancer liver metastases: reappraisal in the era of modern chemotherapy. World J Surg 2013;37:26472654.

36 Andreou A, Aloia TA, Brouquet A, et al: Margin status remains an important determinant of survival after surgical resection of colorectal liver metastases in the era of modern chemotherapy. Ann Surg 2013;257: 1079-1088.

37 Lee Y-M: Local and regional recurrence of carcinoma of the colon and rectum: I. tumour-host factors and adjuvant therapy. Surg Oncol 1995;4:283-293.

38 Nordlinger B, Malafosse R, Anak O: The European Organization for Research and Treatment of Cancer Gastrointestinal Group Trials: surgery and liver surgery in Europe. Surg Oncol Clin N Am 2001;10:795-806, ix.

39 Goyer P, Karoui M, Vigano L, et al: Single-center multidisciplinary management of patients with colorectal cancer and resectable synchronous liver metastases improves outcomes. Clin Res Hepatol Gastroenterol 2013;37:47-55.

40 Sugarbaker PH: Colorectal cancer: prevention and management of metastatic disease. Biomed Res Int 2014;2014:782890.

41 Veereman G, Robays J, Verleye L, et al: Pooled analysis of the surgical treatment for colorectal cancer liver metastases. Crit Rev Oncol Hematol 2015;94:122-135.

42 Slesser AA, Khan F, Chau I, et al: The effect of a primary tumour resection on the progression of synchronous colorectal liver metastases: an exploratory study. Eur J Surg Oncol 2015;41:484-492.

43 Yin Z, Liu C, Chen Y, et al: Timing of hepatectomy in resectable synchronous colorectal liver metastases (SCRLM): simultaneous or delayed? Hepatology 2013; 57:2346-2357.

44 Chen J, Li Q, Wang C, Zhu H, Shi Y, Zhao G: Simultaneous vs. staged resection for synchronous colorectal liver metastases: a meta-analysis. Int J Colorectal Dis 2011;26:191-199.

45 Brouquet A, Abdalla EK, Kopetz S, et al: High survival rate after two-stage resection of advanced colorectal liver metastases: response-based selection and complete resection define outcome. J Clin Oncol 2011;29: 1083-1090.
6 Slesser AA, Chand M, Goldin R, Brown G, Tekkis PP, Mudan S: Outcomes of simultaneous resections for patients with synchronous colorectal liver metastases. Eur J Surg Oncol 2013;39:1384-1393.

47 Mentha G, Majno P, Terraz S, et al: Treatment strategies for the management of advanced colorectal liver metastases detected synchronously with the primary tumour. Eur J Surg Oncol 2007;33(suppl 2):S76-83.

48 Sun Z, Tang W, Sakamoto Y, Hasegawa K, Kokudo N: A systematic review and meta-analysis of feasibility, safety and efficacy of associating liver partition and portal vein ligation for staged hepatectomy (ALPPS) versus two-stage hepatectomy (TSH). Biosci Trends 2015;9:284-288.

49 Bertens KA, Hawel J, Lung K, Buac S, Pineda-Solis K, Hernandez-Alejandro R: ALPPS: challenging the concept of unresectability - a systematic review. Int J Surg 2015;13:280-287.

50 Lam VW, Laurence JM, Johnston E, Hollands MJ, Pleass HC, Richardson AJ: A systematic review of twostage hepatectomy in patients with initially unresectable colorectal liver metastases. HPB (Oxford) 2013;15: 483-491.

51 Abdalla EK: Portal vein embolization (prior to major hepatectomy) effects on regeneration, resectability, and outcome. J Surg Oncol 2010;102:960-967.

52 Schadde E, Schnitzbauer AA, Tschuor C, Raptis DA, Bechstein WO, Clavien PA: Systematic review and meta-analysis of feasibility, safety, and efficacy of a novel procedure: associating liver partition and portal vein ligation for staged hepatectomy. Ann Surg Oncol 2015;22:3109-3120.

53 Nikfarjam M, Shereef S, Kimchi ET, et al: Survival outcomes of patients with colorectal liver metastases following hepatic resection or ablation in the era of effective chemotherapy. Ann Surg Oncol 2009;16:1860-1867.

54 Adam R, Lucidi V, Bismuth H: Hepatic colorectal metastases: methods of improving resectability. Surg Clin North Am 2004;84:659-671.

55 Baron O, Amini M, Duveau D, Despins P, Sagan CA, Michaud JL: Surgical resection of pulmonary metastases from colorectal carcinoma. Five-year survival and main prognostic factors. Eur J Cardiothorac Surg 1996;10: 347-351.

56 Cho JH, Kim S, Namgung M, et al: The prognostic importance of the number of metastases in pulmonary metastasectomy of colorectal cancer. World J Surg Oncol 2015;13:222.

57 Saito Y, Omiya H, Kohno K, et al: Pulmonary metastasectomy for 165 patients with colorectal carcinoma: a prognostic assessment. J Thorac Cardiovasc Surg 2002; 124:1007-1013.

58 Dave RV, Pathak S, White AD, et al: Outcome after liver resection in patients presenting with simultaneous hepatopulmonary colorectal metastases. Br J Surg 2015;102:261-268

59 Sakamoto Y, Sakaguchi Y, Oki E, Minami K, Toh Y, Okamura T: Surgical outcomes after resection of both hepatic and pulmonary metastases from colorectal cancer. World J Surg 2012;36:2708-2713.

60 Park JK, Kim YW, Hur H, et al: Prognostic factors affecting oncologic outcomes in patients with locally recurrent rectal cancer: impact of patterns of pelvic recurrence on curative resection. Langenbecks Arch Surg 2009;394:71-77.

61 Rahbari NN, Ulrich AB, Bruckner T, et al: Surgery for locally recurrent rectal cancer in the era of total mesorectal excision: is there still a chance for cure? Ann Surg 2011;253:522-533.

62 Asoglu O, Matlim T, Karanlik H, et al: Impact of laparoscopic surgery on bladder and sexual function after total mesorectal excision for rectal cancer. Surg Endosc 2009;23:296-303. 
63 Akiyoshi T, Fujimoto Y, Konishi T, et al: Prognostic factors for survival after salvage surgery for locoregional recurrence of colon cancer. Am J Surg 2011;201: 726-733.

64 van der Meij W, Rombouts AJ, Rütten H, Bremers AJ, de Wilt JH: Treatment of locally recurrent rectal carcinoma in previously (chemo)irradiated patients: a review. Dis Colon Rectum 2016;59:148-156.

65 Read TE, Mutch MG, Chang BW, et al: Locoregional recurrence and survival after curative resection of adenocarcinoma of the colon. J Am Coll Surg 2002;195 $33-40$.

66 Bowne WB, Lee B, Wong WD, et al: Operative salvage for locoregional recurrent colon cancer after curative resection: an analysis of 100 cases. Dis Colon Rectum 2005;48:897-909.

67 Brandi G, Corbelli J, de Rosa F, et al: Second surgery or chemotherapy for relapse after radical resection of colorectal cancer metastases. Langenbecks Arch Surg 2012;397:1069-1077.

68 Pulitanò C, Bodingbauer M, Aldrighetti L, et al: Liver resection for colorectal metastases in presence of extrahepatic disease: results from an international multi-institutional analysis. Ann Surg Oncol 2011;18:13801388.

69 Saito N, Koda K, Takiguchi N, et al: Curative surgery for local pelvic recurrence of rectal cancer. Dig Surg 2003;20:192-200.

70 Martling AL, Holm T, Rutqvist LE, Moran BJ, Heald RJ, Cedemark B: Effect of a surgical training programme on outcome of rectal cancer in the county of Stockholm. Stockholm Colorectal Cancer Study Group, Basingstoke Bowel Cancer Research Project. Lancet 2000;356:93-96

71 West NP, Anderin C, Smith KJ, Holm T, Quirke P; European Extralevator Abdominoperineal Excision Study Group: Multicentre experience with extralevator abdominoperineal excision for low rectal cancer. Br J Surg 2010;97:588-599.

72 Pearlman NW, Donohue RE, Stiegmann GV, Ahnen DJ, Sedlacek SM, Braun TJ. Pelvic and sacropelvic exenteration for locally advanced or recurrent anorectal cancer. Arch Surg 1987;122:537-541.

73 Wanebo HJ, Gaker DL, Whitehill R, Morgan RF, Constable WC: Pelvic recurrence of rectal cancer. Options for curative resection. Ann Surg 1987;205:482-495.

74 Sugarbaker PH: Partial sacrectomy for en bloc excision of rectal cancer with posterior fixation. Dis Colon Rectum 1982;25:708-711.

75 Steele SR, Chang GJ, Hendren S, et al: Practice guideline for the surveillance of patients after curative treatment of colon and rectal cancer. Dis Colon Rectum 2015;58:713-725.

76 Ketcham AS: The management of recurrent rectal carcinoma. Can J Surg 1985;28:422-424.
Moffat FL, Falk RE: Radical surgery for extensive rectal cancer: is it worthwhile? Recent Results Cancer Res 1998;146:71-83.

78 Kim HK, Jessup JM, Beard CJ, et al: Locally advanced rectal carcinoma: pelvic control and morbidity following preoperative radiation therapy, resection, and intraoperative radiation therapy. Int J Radiat Oncol Biol Phys 1997;38:777-783.

79 Valentini V, Morganti AG, Gambacorta MA, et al: Preoperative hyperfractionated chemoradiation for locally recurrent rectal cancer in patients previously irradiated to the pelvis: a multicentric phase II study. Int J Radiat Oncol Biol Phys 2006;64:1129-1139.

80 Dresen RC, Peters EE, Rutten HJ, et al: Local recurrence in rectal cancer can be predicted by histopathological factors. Eur J Surg Oncol 2009;35:1071-1077.

81 Bosman SJ, Vermeer TA, Dudink RL, de Hingh IH, Nieuwenhuijzen GA, Rutten HJ: Abdominosacral resection: long-term outcome in 86 patients with locally advanced or locally recurrent rectal cancer. Eur J Surg Oncol 2014;40:699-705.

82 Glehen O, Osinsky D, Cotte E, et al: Intraperitoneal chemohyperthermia using a closed abdominal procedure and cytoreductive surgery for the treatment of peritoneal carcinomatosis: morbidity and mortality analysis of 216 consecutive procedures. Ann Surg Oncol 2003; 10:863-869.

83 Glockzin G, Ghali N, Lang SA, Schlitt HJ, Piso P: Results of cytoreductive surgery and hyperthermic intraperitoneal chemotherapy for peritoneal carcinomatosis from colorectal cancer. J Surg Oncol 2009;100:306310.

84 Koppe MJ, Boerman OC, Oyen WJ, Bleichrodt RP: Peritoneal carcinomatosis of colorectal origin: incidence and current treatment strategies. Ann Surg 2006; 243:212-222

85 Arjona-Sánchez A, Medina-Fernández FJ, MuñozCasares FC, Casado-Adam A, Sánchez-Hidalgo JM, Rufián-Peña S: Peritoneal metastases of colorectal origin treated by cytoreduction and HIPEC: an overview. World J Gastrointest Oncol 2014;6:407-412.

86 Elias D, Lefevre JH, Chevalier J, et al: Complete cytoreductive surgery plus intraperitoneal chemohyperthermia with oxaliplatin for peritoneal carcinomatosis of colorectal origin. J Clin Oncol 2009;27:681-685.

87 Elias D, Benizri E, Di Pietrantonio D, Menegon P, Malka D, Raynard B: Comparison of two kinds of intraperitoneal chemotherapy following complete cytoreductive surgery of colorectal peritoneal carcinomatosis. Ann Surg Oncol 2007;14:509-514.

88 Sugarbaker PH, Jablonski KA: Prognostic features of 51 colorectal and 130 appendiceal cancer patients with peritoneal carcinomatosis treated by cytoreductive surgery and intraperitoneal chemotherapy. Ann Surg 1995; 221:124-132.
89 Verwaal VJ, Bruin S, Boot H, van Slooten G, van Tinteren $\mathrm{H}$ : 8-year follow-up of randomized trial: cytoreduction and hyperthermic intraperitoneal chemotherapy versus systemic chemotherapy in patients with peritoneal carcinomatosis of colorectal cancer. Ann Surg Oncol 2008;15:2426-2432.

90 Yan TD, Black D, Savady R, Sugarbaker PH: Systematic review on the efficacy of cytoreductive surgery combined with perioperative intraperitoneal chemotherapy for peritoneal carcinomatosis from colorectal carcinoma. J Clin Oncol 2006;24:4011-4019.

91 Glehen O, Kwiatkowski F, Sugarbaker PH, et al: Cytoreductive surgery combined with perioperative intraperitoneal chemotherapy for the management of peritoneal carcinomatosis from colorectal cancer: a multi-institutional study. J Clin Oncol 2004;22:32843292

92 Mahteme H, Hansson J, Berglund A, Påhlman L, Glimelius B, Nygren P, Graf W: Improved survival in patients with peritoneal metastases from colorectal cancer: a preliminary study. Br J Cancer 2004;90:403407.

93 Cotte E, Passot G, Gilly FN, Glehen O: Selection of patients and staging of peritoneal surface malignancies. World J Gastrointest Oncol 2010;2:31-35.

94 Riss S, Mohamed F, Dayal S, Cecil T, Stift A, Bachleitner-Hofmann T, Moran B: Peritoneal metastases from colorectal cancer: patient selection for cytoreductive surgery and hyperthermic intraperitoneal chemotherapy. Eur J Surg Oncol 2013;39:931-937.

95 Verwaal VJ, van Ruth S, de Bree E, van Sloothen GW, van Tinteren H, Boot H, Zoetmulder FA: Randomized trial of cytoreduction and hyperthermic intraperitoneal chemotherapy versus systemic chemotherapy and palliative surgery in patients with peritoneal carcinomatosis of colorectal cancer. J Clin Oncol 2003;21: 3737-3743.

96 Elias D, Gilly F, Boutitie F, et al: Peritoneal colorectal carcinomatosis treated with surgery and perioperative intraperitoneal chemotherapy: retrospective analysis of 523 patients from a multicentric French study. J Clin Oncol 2010;28:63-68.

97 Chua TC, Yan TD, Ng KM, Zhao J, Morris DL: Significance of lymph node metastasis in patients with colorectal cancer peritoneal carcinomatosis. World J Surg 2009;33:1488-1494.

98 da Silva RG, Sugarbaker PH: Analysis of prognostic factors in seventy patients having a complete cytoreduction plus perioperative intraperitoneal chemotherapy for carcinomatosis from colorectal cancer. J Am Coll Surg 2006;203:878-886.

99 Greten TF, Malek NP, Schmidt S, et al: Diagnosis of and therapy for hepatocellular carcinoma (Article in German). Z Gastroenterol 2013;51:1269-1326. 